\title{
Update in Achalasia - what the surgeon needs to know
}

\author{
AUTHORS \\ Hamer $\mathrm{PW}^{1}$, Holloway $\mathrm{RH}^{2}$, Crosthwaite $\mathrm{G}^{3,4}$, Devitt $\mathrm{PG}^{1}$, Thompson $\mathrm{SK}^{1,5}$ \\ (?) \\ ${ }^{1}$ University of Adelaide Discipline of Surgery, Royal Adelaide Hospital, Adelaide, South \\ Australia \\ ${ }^{2}$ Department of Gastroenterology and Hepatology, Royal Adelaide Hospital, North Terrace, \\ South Australia \\ ${ }^{3}$ Department of Surgery, The University of Melbourne, Parkville, Victoria, Australia \\ ${ }^{4}$ Clinical Institute General Surgery and Gastroenterology Epworth Healthcare \\ ${ }^{5}$ University of South Australia, Adelaide, South Australia \\ CORRESPONDING AUTHOR \\ Associate Professor Sarah K Thompson. Discipline of Surgery, Level 5, Eleanor Harrald \\ Building, Royal Adelaide Hospital, North Terrace, Adelaide, South Australia, 5000. Email: \\ Sarah.Thompson@adelaide.edu.au..Ph: +61 882225516.

\section{WORD COUNT} \\ 3237 including abstract, main text, figure legends and references \\ 3 figures, 1 table at 250 words each $=1000$ words \\ Total 4237
}

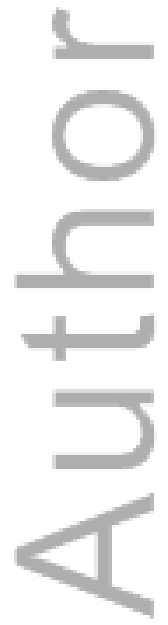

This is the author manuscript accepted for publication and has undergone full peer review but has not been through the copyediting, typesetting, pagination and proofreading process, which may lead to differences between this version and the Version of Record. Please cite this article as doi: 10.1111/ans.13497

This article is protected by copyright. All rights reserved. 


\section{ABSTRACT}

Achalasia is a motility disorder encountered by surgeons during the investigation and treatment of dysphagia. Recent advances in manometry technology, a widely accepted new classification system and a new treatment rapidly gaining international acceptance have changed the working knowledge required to successfully manage patients with achalasia. We review the Chicago classification subtypes of achalasia with type II achalasia being a predictor of success and type III achalasia a predictor of treatment failure. We review peroral endoscopic myotomy as an emerging treatment option and its potential for improving the treatment of type III achalasia.

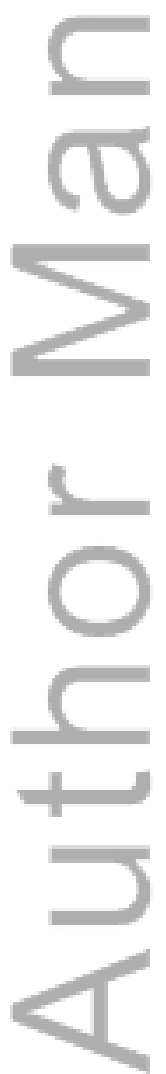

This article is protected by copyright. All rights reserved. 


\section{INTRODUCTION}

Achalasia remains the most distinctive albeit relatively rare of the motility disorders of the oesophagus. Significant changes to understanding and treatment of the disease have occurred over the last decade. The Chicago classification system, now widely accepted into clinical practice, has identified subtypes of achalasia that have been shown to predict $\rightarrow$ response to myotomy or dilation. Type III achalasia is the strongest predictor of failure with type II achalasia a predictor of success. A new treatment for achalasia, per-oral endoscopic myotomy (POEM), a natural orifice transluminal endoscopic surgery (NOTES) procedure, is developing acceptance but consensus has not been reached on appropriate indications. We review POEM and discuss its potential place in the treatment of achalasia.

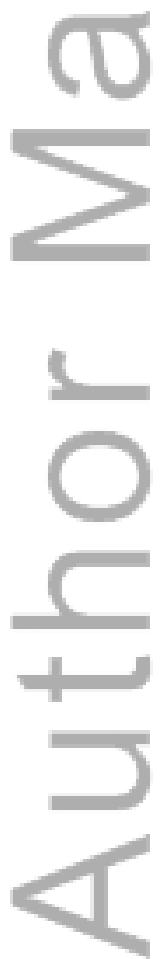

This article is protected by copyright. All rights reserved. 


\section{MANOMETRY}

The diagnosis of achalasia is based on the finding of failure of relaxation of the lower oesophageal sphincter, aperistalsis of the oesophageal body, and the exclusion of malignancy or obstruction - so called 'pseudoachalasia'. Classical symptoms of dysphagia, regurgitation, chest pain, and weight loss are not always present and if present, are often misinterpreted by patients and clinicians as reflux.

Whilst endoscopy and barium swallow are mandatory in the assessment and diagnosis of achalasia, manometry is the diagnostic gold standard. The hallmarks are both incomplete lower oesophageal sphincter (LOS) relaxation after pharyngeal initiation of a swallow and oesophageal aperistalsis. Recently, high resolution solid state catheters using electronic pressure sensors at $1 \mathrm{~cm}$ spacings have been introduced into clinical practice and are beginning to replace water-perfused systems. Although many water-perfused systems give a similar resolution across the LOS, the solid-state catheters give high resolution over the entire length of the oesophagus. The transducers require zeroing for temperature only, compared to water-perfused systems where the reading can be influenced by the pump and pressure in the catheter tubing, as well as gravity and position of the catheter relative to the transducer. Solid-state catheters and their corresponding software analyse the tracing using metrics described by a high resolution manometry working party (the Chicago classification, described in more detail in the next section), and the terminology differs from that used 
with traditional water-perfused systems (Table 1). These metrics are clearly defined and calculated automatically by computer software then checked by the reporting clinician. Along with more accurate measurements, this allows for greater standardisation and less inter-observer variability.

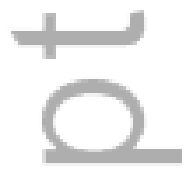

$=$
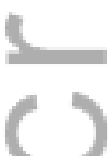

$\infty$

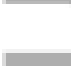

C.
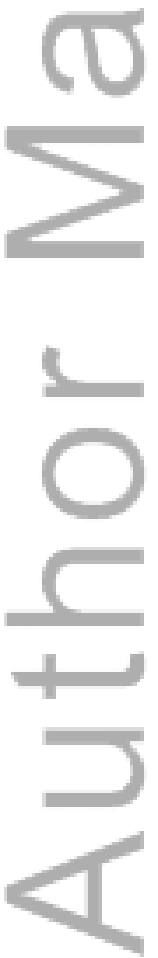

This article is protected by copyright. All rights reserved. 


\section{THE CHICAGO CLASSIFICATION}

The Chicago classification classifies achalasia patients into 3 subtypes based on the pattern of the oesophageal body dysfunction, which occurs concurrently with the failure of the lower oesophageal sphincter (LOS) to relax. A fourth group, oesophago-gastric junction obstruction, is also described where oesophageal peristalsis is preserved. This group may in some cases represent an evolving achalasia but can also be due to mechanical obstruction, more likely than in the achalasia group subtypes $(1,2)$.

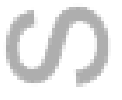

\section{Type I achalasia}

Type I achalasia is characterised by minimal oesophageal body function, peristaltic or otherwise, with only low level oesophageal pressurisations of $<30 \mathrm{mmHg}(3,4)$ (Figure 1a). It is thought to represent a later presentation of type II achalasia with more extensive neural loss, leading to minimal oesophageal body function, peristaltic or otherwise. It represents $25-40 \%$ of patients. Fitting with the hypothesis of a later presentation, these patients often have dilation of the oesophageal body as shown on barium swallow (Figure 2a).

\section{Type II achalasia}

Type II achalasia is the most frequently encountered type of achalasia with $50-65 \%$ of patients falling into this category. It is characterised by more substantial pan-oesophageal pressurisations $(>30 \mathrm{mmHg}$ ) indicative of a degree of preserved albeit pathological 
oesophageal muscle function (Figure $1 \mathrm{~b}$ ). This residual oesophageal muscle function is thought to correlate with less myenteric neuronal loss than in type I achalasia, probably due to an earlier presentation of the disease. The pressurisations that are seen are due to residual longitudinal and circular muscle contractions(5). These patients often have the typical bird's beak appearance on barium study but generally have not yet progressed to oesophageal dilation (Figure $2 b$ ).

\section{Type III achalasia}

The group of patients with type III achalasia represent overlap with what was known as vigorous or spastic achalasia. They are a group of patients where the body of the oesophagus exhibits spastic activity in addition to failure of the lower oesophageal sphincter to relax. This spasm is different from the pan oesophageal pressurisation found in types I and II as it is in the distal two thirds of the oesophagus, it is premature (defined by distal latency), and it generally has a higher pressure (1) (Figure 1c). Patients with type III achalasia have preservation of myenteric neurons but impaired inhibitory post-ganglionic neural function (4). The circular muscle still functions but exhibits unco-ordinated rather than absent contractions $(4,5)$. On barium swallow, the spasm is sometimes shown as a corkscrew appearance similar to that seen in diffuse oesophageal spasm (Figure 2c). In these patients, the lower oesophageal sphincter may also be slightly longer $(4-5 \mathrm{~cm}$ vs. $3-4 \mathrm{~cm}$ in types I and II (6)) than seen in the other subtypes. Type III achalasia is the least common of the 3 subtypes making up only about $10 \%$ of achalasia patients. 


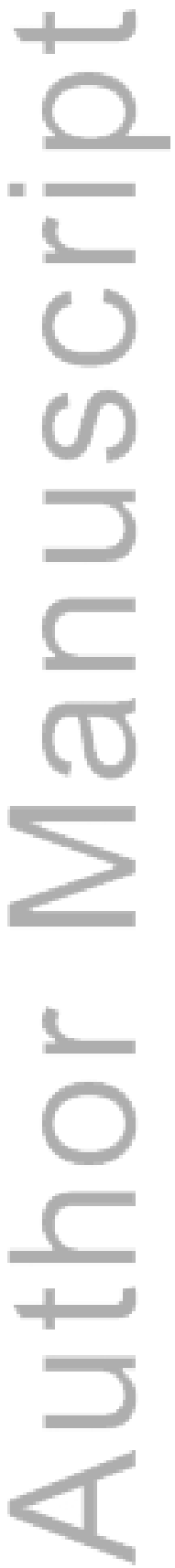

This article is protected by copyright. All rights reserved. 


\section{IMPACT OF MANOMETRIC SUBTYPE ON TREATMENT OUTCOME}

Type II achalasia has the best response to either cardiomyotomy or pneumatic dilatation with a greater than $95 \%$ success rate $(6,7)$. A presentation at an early stage of the disease correlates with residual oesophageal muscle function that aids oesophageal emptying after disruption of the LOS (4).

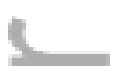

Type I achalasia patients have an almost complete loss of oesophageal muscle function and greater oesophageal dilation. Success rates with laparoscopic myotomy or pneumatic dilation in this group are slightly lower, in the order of $80-85 \%(6,7)$.

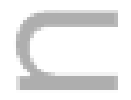

The clinical significance of type III achalasia is that the response to cardiomyotomy or pneumatic dilatation are only around $50 \%(3,6,7)$. Perhaps the reason that disruption of the LOS in type III patients does not always work is that the treatment addresses only half of the disease, namely the sphincter, and not the oesophageal body. The spasm in a type III patient remains untreated and may be the cause of residual symptoms such as pain, regurgitation, and dysphagia. Another potential reason for a suboptimal response in type III achalasia could be an inadequate myotomy with failure to provide a myotomy of sufficient length to cover the longer sphincter length that may occur. This issue has led to the adoption of the term 'long myotomy' by some gastroenterologists. The term means a slightly 
longer myotomy across the GOJ (to cover this extra length), rather than a traditional long myotomy (to the level of the azygos vein).

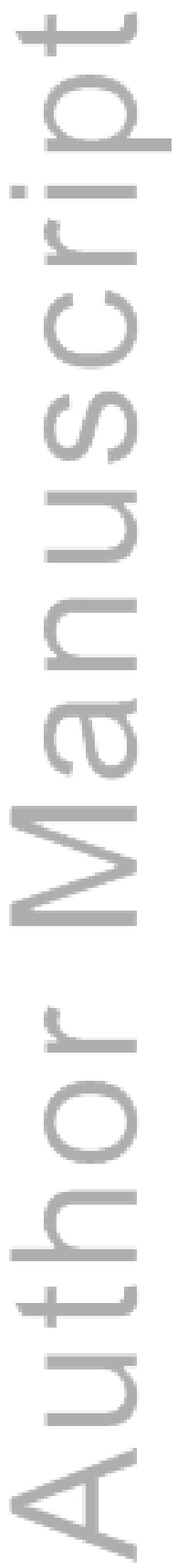

This article is protected by copyright. All rights reserved. 


\section{WHERE DOES POEM FIT IN?}

Whilst laparoscopic cardiomyotomy with partial fundoplication remains the gold standard for treatment of achalasia $(8,9)$, there is debate on whether per-oral endoscopic myotomy has equivalent results in type I and type II achalasia or even superiority in type III achalasia patients who have a poorer response to traditional treatment.

\section{What is POEM?}

Per-oral endoscopic myotomy (POEM) involves the creation of an endoscopic submucosal tunnel, followed by division of the circular muscle layer of the distal oesophagus, LOS, and cardia (Figure 3). Advantages of POEM include its relative non-invasive nature (i.e. endoscopic rather than operative procedure), and the longer length of myotomy. Disadvantages include the requirement of advanced endoscopic technical skills, the substantial learning curve in a relatively uncommon disease, and the lack of long-term follow up.

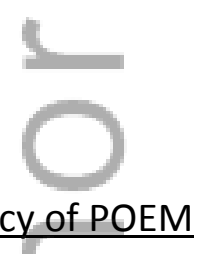

\section{Efficacy of POEM}

Short term outcomes for POEM are promising. High volume centres are reporting success rates in the order of $91 \%(n=423)$ which persist at three year follow-up $89 \%(n=61)(10)$ and smaller western series show similar results $(11,12)$. It must be noted that these are prospective cohort studies and as yet there has been no randomised controlled trial to 
compare POEM to conventional therapies (cardiomyotomy or pneumatic dilatation)(10, 13). It would however, seem intuitive that we can predict long-term outcomes by applying first principles. A POEM, like a laparoscopic cardiomyotomy, divides the lower oesophageal sphincter muscles under direct vision rather than tearing them in a less controlled manner as occurs with pneumatic dilatation. This clean division underlies the lower re-intervention rate seen after cardiomyotomy compared to pneumatic dilatation, which usually requires at least two or three repeat interventions. One would expect a similar long-term outcome in POEM patients with effective relief of dysphagia with five-year success rates at least $76 \%$ (9) and perhaps as high as $87 \%(14)$.

\section{Is reflux a concern?}

POEM, unlike a laparoscopic cardiomyotomy, does not include an anti-reflux procedure. Whether or not this is detrimental is unclear. In laparoscopic cardiomyotomy, reflux occurs postoperatively in $41.5 \%$ of patients if a fundoplication is omitted, and is often asymptomatic $(15,16)$. However, the high rate of pathological reflux has led to the adoption of Heller's cardiomyotomy with partial fundoplication as the gold standard (Society of American Gastrointestinal and Endoscopic Surgeons - strong recommendation), and this lowers the reflux rate to $14.5 \%$ (16). After pneumatic dilation, rates are in the order of $23-$ $31 \%(17,18)$. Achalasia patients have a long life expectancy and leaving them with potentially decades of pathological reflux is a concern. Not only does opening the gastrooesophageal junction lead to reflux but also oesophageal clearance of reflux is impaired due 
to the underlying oesophageal body dysmotility. Over time, uncontrolled reflux leads to peptic strictures resulting in dysphagia, the very problem that led to treatment in the first place. Also of concern is the reflux - metaplasia - dysplasia - adenocarcinoma sequence established in the Barrett's literature $(19,20)$. Our institution's recent endoscopic review of 68 achalasia patients at least 5 years post-cardiomyotomy, uncovered $7 \%$ with unsuspected Barrett's oesophagus (20).

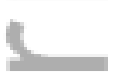

All treatments for achalasia disrupt the anti-reflux mechanisms of the gastro-oesophageal junction (GOJ). Surgical cardiomyotomy, in addition to dividing the lower oesophageal sphincter, also includes division of the phreno-oesophageal ligament, which theoretically impairs crural augmentation, as well as loss of the angle of His. These impairments are compensated for by the addition of a partial fundoplication.

POEM divides the lower oesophageal sphincter muscles, theoretically leaving the other mechanisms intact, but does not provide any compensatory anti-reflux procedure. Given the complex multi-factorial nature of acid reflux, and the unknown importance of these antireflux mechanisms relative to each other(21), it is difficult to accurately predict how much reflux will occur after a POEM or in which patients reflux will occur.

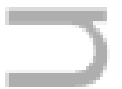

Two significant points have emerged from recent publications with regards to reflux after POEM. First, rates of pathological reflux as determined by objective $\mathrm{pH}$ studies post-POEM 
are between 31 and $88 \%$, with the largest series $(n=73)$ estimating 53\% (11, 22-24). Second, as with laparoscopic cardiomyotomy, there is no correlation between reflux symptoms and objective measures of reflux, as patients with pathological reflux in this cohort are often asymptomatic $(23,24)$. Given the high rate of asymptomatic pathological reflux after POEM, patients should be prepared to undergo objective testing post-POEM, or alternatively, begin empiric treatment with anti-secretory medication.

POEM in type III achalasia

The above arguments relate mostly to type I or type II achalasia. In type III achalasia, POEM has a clearer potential advantage. In type III achalasia, a degree of chest pain, regurgitation, and dysphagia experienced may be due in greater part to oesophageal body spasm, distinct from type I and II achalasia where symptoms are due primarily to GOJ obstruction. The myotomy in POEM can be extended more proximally on the oesophageal side than with a laparoscopic cardiomyotomy, potentially treating oesophageal spasm as well as dividing the lower oesophageal sphincter. The myotomy can also be adjusted to the degree and length of the spasm as demonstrated by high resolution manometry.

The concept of treating type III achalasia with POEM has been supported by a multi-centre retrospective review demonstrating a $96 \%(n=46)$ success in type III achalasia (25). As type III achalasia patients respond poorly to traditional treatments ( $50 \%$ success compared to 80 90\% with types I and II), there is certainly an argument for considering POEM as primary 
therapy for type III achalasia. Given the low incidence of type III achalasia ( $10 \%$ of all achalasia), it is unlikely there will ever be a randomised controlled trial to confirm this. Data suggesting response rates above $90 \%$ for POEM in diffuse oesophageal spasm, a condition similar to type III achalasia but without the raised lower oesophageal sphincter pressures,

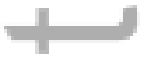
also supports POEM as the potential preferred treatment for type III achalasia, but formal investigation is needed (25).

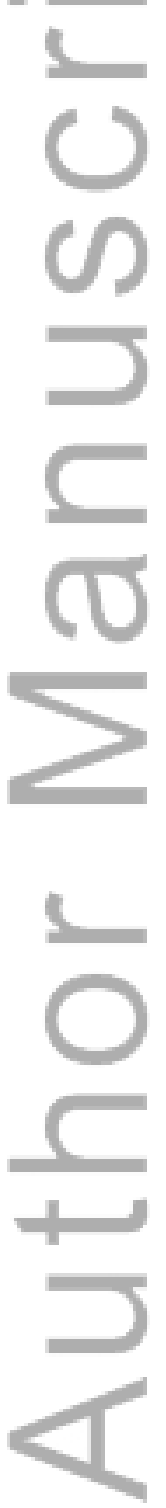

This article is protected by copyright. All rights reserved. 


\section{CONCLUSION}

Advances in manometry technology and a new classification system are driving our understanding of achalasia. Although the treatment of achalasia with a laparoscopic l. cardiomyotomy is the gold standard for relief of dysphagia, it is important to recognise that type III achalasia may not response as well to standard treatment. POEM is an emerging technology that shows promise, especially for treatment of type III achalasia. Rates of asymptomatic reflux are high post-POEM, so patients undergoing POEM need to be counselled and be willing to take long-term anti-secretory medication if necessary.

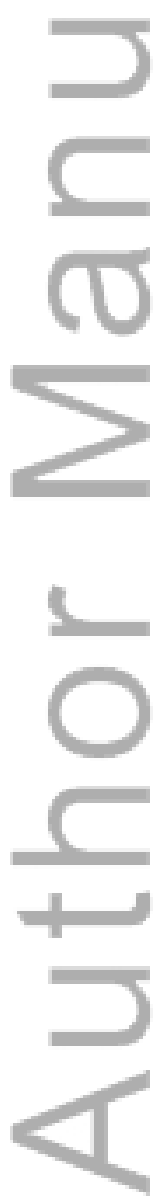

This article is protected by copyright. All rights reserved. 


\section{FIGURE LEGENDS}

Figure 1. High resolution manometry demonstrating achalasia subtypes. Type I (a) characterised by minimal oesophageal pressurisations, type II (b) with pan-oesophageal pressurisation wave (black line demarcates $30 \mathrm{mmHg}$ contour) and type III (c) with premature spastic contractions.

s.

Figure 2. Barium oesophagograms demonstrating type I achalasia (A) with dilated oesophagus and bird's beak appearance at LOS, type II achalasia (B) with non-dilated oesophagus but narrowing at LOS, type III achalasia (C) with corkscrew appearance from spasm in the oesophageal body. (Reproduced with permission of Journal of Neurogastroenterology and Motility(26))

Figure 3. Schematic representation of a POEM procedure, showing the oesophageal mucosa is breached about half way down the oesophagus and the dissection continued in the submucosal plane until the cardia is reached. At that stage the myotomy can be performed to the length determined by the surgeon-endoscopist. (Reproduced with permission of Georg Thieme Verlag KG(27))

This article is protected by copyright. All rights reserved. 


\section{REFERENCES}

1. Kahrilas PJ, Bredenoord AJ, Fox M, Gyawali CP, Roman S, Smout AJ, et al. The Chicago Classification of esophageal motility disorders, v3.0. Neurogastroenterology and motility : the official journal of the European Gastrointestinal Motility Society. 2015;27(2):160-74.

2. Bredenoord AJ, Fox M, Kahrilas PJ, Pandolfino JE, Schwizer W, Smout AJ. Chicago classification criteria of esophageal motility disorders defined in high resolution esophageal pressure topography. Neurogastroenterology and motility : the official journal of the European Gastrointestinal Motility Society. 2012;24 Suppl 1:57-65.

3. = Pandolfino JE, Kwiatek MA, Nealis T, Bulsiewicz W, Post J, Kahrilas PJ. Achalasia: a new clinically relevant classification by high-resolution manometry. Gastroenterology. 2008;135(5):1526-33.

4. Kahrilas PJ, Boeckxstaens G. The spectrum of achalasia: lessons from studies of pathophysiology and high-resolution manometry. Gastroenterology. 2013;145(5):954-65.

5. Mittal RK, Hong SJ, Bhargava V. Longitudinal muscle dysfunction in achalasia esophagus and its relevance. Journal of neurogastroenterology and motility. 2013;19(2):12636.

6. Salvador R, Costantini M, Zaninotto G, Morbin T, Rizzetto C, Zanatta L, et al. The preoperative manometric pattern predicts the outcome of surgical treatment for esophageal achalasia. Journal of gastrointestinal surgery : official journal of the Society for Surgery of the Alimentary Tract. 2010;14(11):1635-45.

7. Rohof WO, Salvador R, Annese V, Bruley des Varannes S, Chaussade S, Costantini $\mathrm{M}$, et al. Outcomes of treatment for achalasia depend on manometric subtype. Gastroenterology. 2013;144(4):718-25; quiz e13-4.

8. Yaghoobi M, Mayrand S, Martel M, Roshan-Afshar I, Bijarchi R, Barkun A. Laparoscopic Heller's myotomy versus pneumatic dilation in the treatment of idiopathic achalasia: a meta-analysis of randomized, controlled trials. Gastrointestinal endoscopy. 2013;78(3):468-75.

9. Weber CE, Davis CS, Kramer HJ, Gibbs JT, Robles L, Fisichella PM. Medium and long-term outcomes after pneumatic dilation or laparoscopic Heller myotomy for achalasia: a meta-analysis. Surgical laparoscopy, endoscopy \& percutaneous techniques. 2012;22(4):28996.

10. Inoue $\mathrm{H}$, Sato $\mathrm{H}$, Ikeda $\mathrm{H}$, Onimaru $\mathrm{M}$, Sato $\mathrm{C}$, Minami $\mathrm{H}$, et al. Per-Oral Endoscopic Myotomy: A Series of 500 Patients. J Am Coll Surg. 2015;221(2):256-64.

11. Teitelbaum EN, Soper NJ, Santos BF, Arafat FO, Pandolfino JE, Kahrilas PJ, et al. Symptomatic and physiologic outcomes one year after peroral esophageal myotomy (POEM) for treatment of achalasia. Surgical endoscopy. 2014.

12. Swanstrom LL, Kurian A, Dunst CM, Sharata A, Bhayani N, Rieder E. Long-term outcomes of an endoscopic myotomy for achalasia: the POEM procedure. Annals of surgery. 2012;256(4):659-67.

13. Ramchandani M, Reddy DN, Darisetty S, Kotla R, Chavan R, Kalpala R, et al. Peroral endoscopic myotomy for Achalasia Cardia: A single center experience of over 200 consecutive patients: treatment analysis and follow up. Dig Endosc. 2015. 
14. Zaninotto G, Costantini M, Rizzetto C, Zanatta L, Guirroli E, Portale G, et al. Four hundred laparoscopic myotomies for esophageal achalasia: a single centre experience. Annals of surgery. 2008;248(6):986-93.

15. Campos GM, Vittinghoff E, Rabl C, Takata M, Gadenstatter M, Lin F, et al. Endoscopic and surgical treatments for achalasia: a systematic review and meta-analysis. Annals of surgery. 2009;249(1):45-57.

16. Stefanidis D, Richardson W, Farrell TM, Kohn GP, Augenstein V, Fanelli RD. SAGES guidelines for the surgical treatment of esophageal achalasia. Surgical endoscopy. 2012;26(2):296-311.

17. Boeckxstaens GE, Annese V, des Varannes SB, Chaussade S, Costantini M, Cuttitta A, et al. Pneumatic dilation versus laparoscopic Heller's myotomy for idiopathic achalasia. The New England journal of medicine. 2011;364(19):1807-16.

18. Novais PA, Lemme EM. 24-h pH monitoring patterns and clinical response after achalasia treatment with pneumatic dilation or laparoscopic Heller myotomy. Alimentary pharmacology \& therapeutics. 2010;32(10):1257-65.

19. Zendehdel K, Nyren O, Edberg A, Ye W. Risk of esophageal adenocarcinoma in achalasia patients, a retrospective cohort study in Sweden. The American journal of gastroenterology. 2011;106(1):57-61.

20. Gossage JA, Devitt PG, Watson DI, Myers JC, Jamieson GG, Thompson SK. Surveillance endoscopy at five or more years after cardiomyotomy for achalasia. Annals of surgery. 2014;259(3):464-8.

21. Herregods TV, Bredenoord AJ, Smout AJ. Pathophysiology of gastroesophageal reflux disease: new understanding in a new era. Neurogastroenterology and motility : the official journal of the European Gastrointestinal Motility Society. 2015;27(9):1202-13. 22. Khashab MA, El Zein M, Kumbhari V, Besharati S, Ngamruengphong S, Messallam A, et al. Comprehensive analysis of efficacy and safety of peroral endoscopic myotomy performed by a gastroenterologist in the endoscopy unit: a single-center experience.

Gastrointestinal endoscopy. 2015.

23. Familiari P, Gigante G, Marchese M, Boskoski I, Tringali A, Perri V, et al. Peroral Endoscopic Myotomy for Esophageal Achalasia: Outcomes of the First 100 Patients With Short-term Follow-up. Annals of surgery. 2015.

24. Jones EL, Meara MP, Schwartz JS, Hazey JW, Perry KA. Gastroesophageal reflux symptoms do not correlate with objective $\mathrm{pH}$ testing after peroral endoscopic myotomy. Surgical endoscopy. 2015.

25. Khashab MA, Messallam AA, Onimaru M, Teitelbaum EN, Ujiki MB, Gitelis ME, et al. International multicenter experience with peroral endoscopic myotomy for the treatment of spastic esophageal disorders refractory to medical therapy (with video). Gastrointestinal endoscopy. 2015;81(5):1170-7.

26. Lee JY, Kim N, Kim SE, Choi YJ, Kang KK, Oh DH, et al. Clinical characteristics and treatment outcomes of 3 subtypes of achalasia according to the chicago classification in a tertiary institute in Korea. Journal of neurogastroenterology and motility. 2013;19(4):485-94. 27. Inoue H, Minami H, Kobayashi Y, Sato Y, Kaga M, Suzuki M, et al. Peroral endoscopic myotomy (POEM) for esophageal achalasia. Endoscopy. 2010;42(4):265-71. 


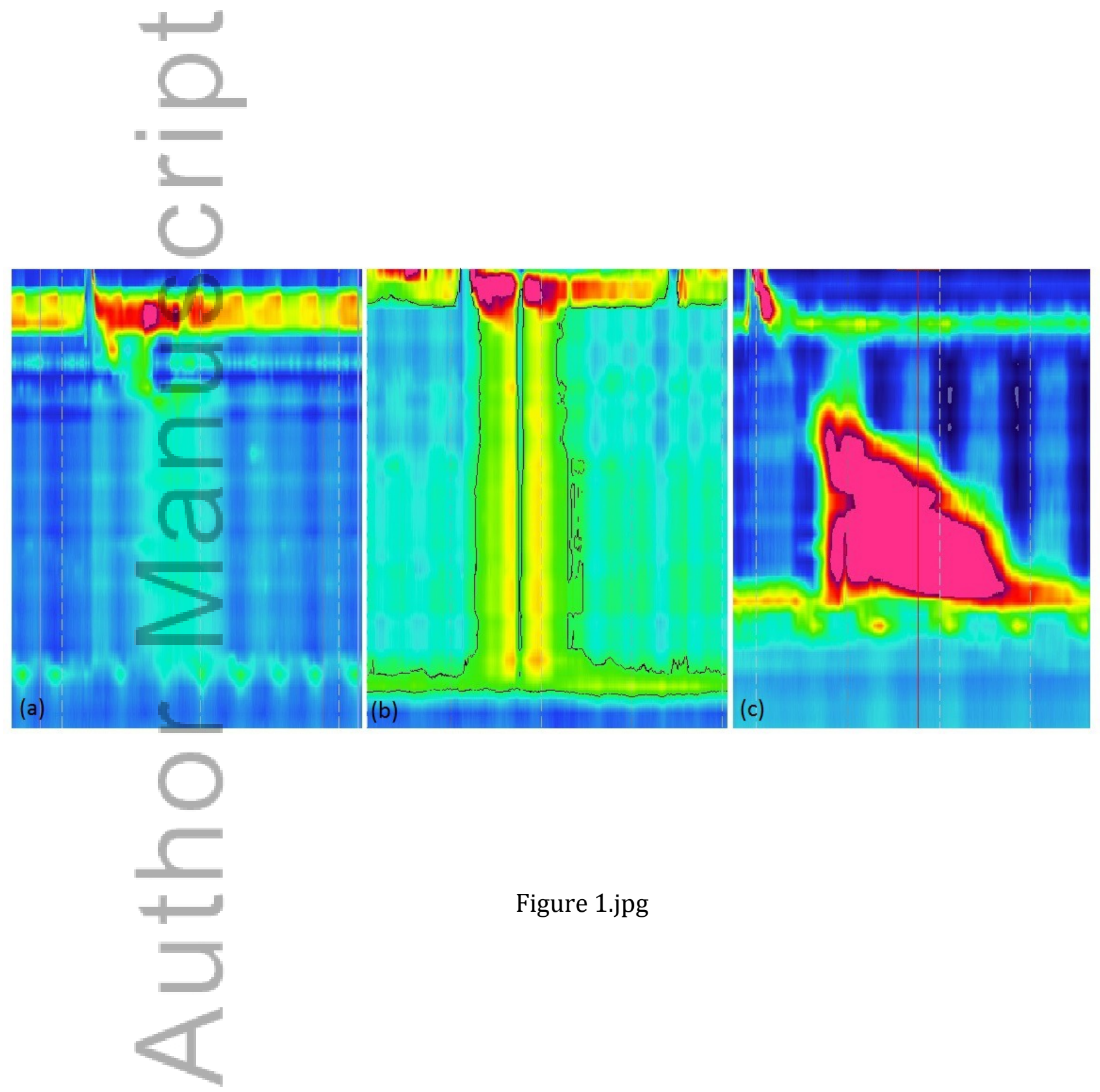

This article is protected by copyright. All rights reserved. 

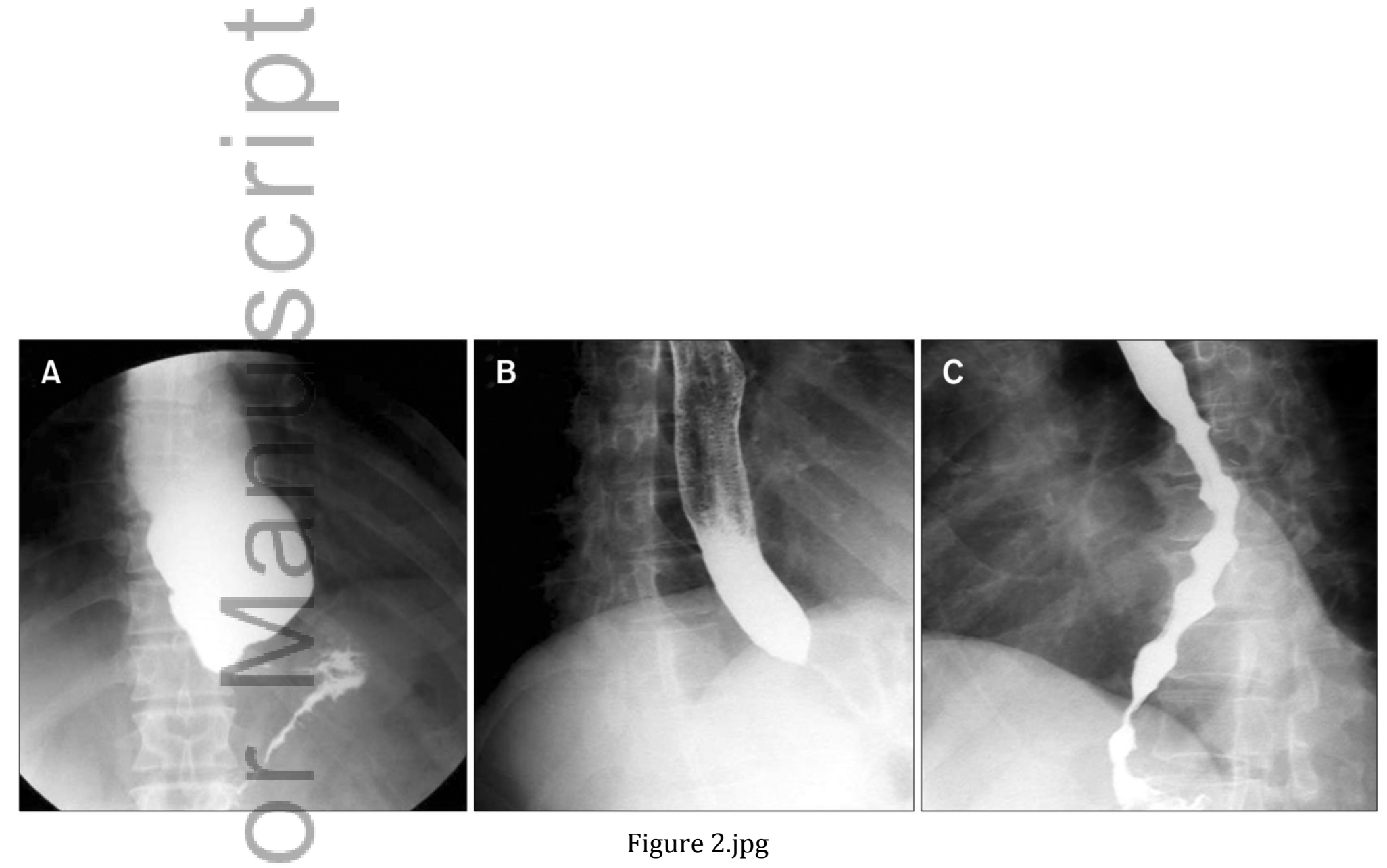

Figure 2.jpg

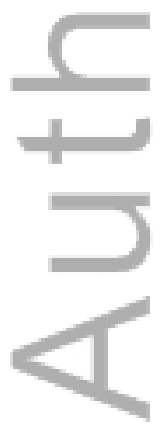

This article is protected by copyright. All rights reserved. 


\section{University Library}

\section{- M M N E R VA A gateway to Melbourne's research publications}

Minerva Access is the Institutional Repository of The University of Melbourne

Author/s:

Hamer, PW;Holloway, RH;Crosthwaite, G;Devitt, PG;Thompson, SK

Title:

Update in achalasia: what the surgeon needs to know

Date:

2016-07-01

Citation:

Hamer, P. W., Holloway, R. H., Crosthwaite, G., Devitt, P. G. \& Thompson, S. K. (2016).

Update in achalasia: what the surgeon needs to know. ANZ JOURNAL OF SURGERY, 86 (7-8), pp.555-559. https://doi.org/10.1111/ans.13497.

Persistent Link:

http://hdl.handle.net/11343/291077 